\title{
IRF4 is Correlated with the Conversion to a Th I7-Like Phenotype in Regulatory T Cells from the Malignant Pleural Effusion
}

\author{
Wenqing $\mathrm{Yu} \mathbb{D}^{1, *}$ \\ Ningfei $\mathrm{Ji}^{2}, *$ \\ Chengjing $\mathrm{Gu}^{3, *}$ \\ Juan $\mathrm{Yao}^{4}$ \\ Mingdong Ding' \\ Daming Zhou' \\ Mao Huang ${ }^{2}$ \\ Mingshun Zhang $\mathbb{D}^{5,6}$ \\ 'Department of Infectious Diseases, Taizhou \\ People's Hospital Affiliated to Nantong \\ University, Taizhou, Jiangsu, 225300, People's \\ Republic of China; ${ }^{2}$ Department of \\ Respiratory and Critical Care Medicine, The \\ First Affiliated Hospital of Nanjing Medical \\ University, Nanjing, Jiangsu, 210029, People's \\ Republic of China; ${ }^{3}$ Department of \\ Pharmacy, Taizhou People's Hospital \\ Affiliated to Nantong University, Taizhou, \\ Jiangsu, 225300, People's Republic of China; \\ ${ }^{4}$ Department of Oncology, Huaian Hospital \\ of Huaian City, Huaian, Jiangsu, 223200, \\ People's Republic of China; ${ }^{5}$ Department of \\ Immunology, Nanjing Medical University, \\ Nanjing, Jiangsu, 2III66, People's Republic \\ of China; ${ }^{6} \mathrm{NHC}$ Key Laboratory of \\ Antibody Technique, Nanjing Medical \\ University, Nanjing, Jiangsu, 2 I I 66, People's \\ Republic of China \\ *These authors contributed equally to this \\ work
}

Correspondence: Chengjing Gu Department of Pharmacy, Taizhou People's Hospital Affiliated to Nantong University, Taizhou, Jiangsu, 225300,

People's Republic of China

Tel +86 0523-86606290

Email chengjingyu706@163.com

Wenqing Yu

Department of Infectious Diseases, Taizhou People's Hospital Affiliated to Nantong University, Taizhou, Jiangsu, 225300, People's Republic of China

Email wenqinggu706@126.com
Background: ROR $\gamma \mathrm{t}^{+} \mathrm{Foxp}^{+}$(Th17-like) Tregs are a plastic Treg subset implicated in immune-related diseases; however, the mechanism of Treg phenotypic transformation in malignant pleural effusion (MPE) has not been elucidated.

Methods: The percentage of $\mathrm{CD}^{+}{ }^{+} \mathrm{CD} 25^{+} \mathrm{Foxp}^{+}{ }^{+} \mathrm{Helios}^{+}$and ROR $\gamma \mathrm{t}^{+} \mathrm{Foxp} 3^{+}$Tregs from peripheral blood and pleural effusion mononuclear cells were measured. The level of interferon regulatory factor 4 (IRF4) mRNA expression was detected by quantitative real-time reverse transcription polymerase chain reaction. The effects of IRF4 on the induction of Tregs from patients with non-small cell lung cancer (NSCLC) were evaluated in vitro. Correlation assays between IRF4 expression and the frequency of ROR $\gamma \mathrm{t}^{+} \mathrm{Foxp} 3^{+}$Tregs were performed.

Results: The frequency of $\mathrm{CD} 4{ }^{+} \mathrm{CD} 25^{+} \mathrm{Foxp}^{+}{ }^{+} \mathrm{Helios}^{+}$Tregs and $\mathrm{CD} 4{ }^{+} \mathrm{ROR} \gamma \mathrm{t}^{+}$Th17 cells was both increased in the MPE of NSCLC patients. The group of double-positive Foxp $3^{+} \mathrm{ROR} \gamma \mathrm{t}^{+}$Treg phenotype were identified in the pleural effusion. A significant increase in the frequency of Foxp $3^{+} \mathrm{ROR} \gamma \mathrm{t}^{+}$Tregs was found in MPE compared with the nonmalignant pleural effusion (NPE). Compared to NPE, the relative level of IRF4 expression was increased in the MPE. IRF4 expression was positively associated with the frequency of Foxp $3^{+} \mathrm{ROR} \gamma \mathrm{t}^{+}$Tregs in the PE. In vitro, the level of Helios mRNA and protein expression was reduced in induced Tregs following IRF4 over-expression. Additionally, the level of ROR $\gamma$ t protein expression was substantially increased. However, ectopic Helios expression in induced Tregs reversed the effects induced by enhanced IRF4 expression.

Conclusion: IRF4 may serve as a potential molecule that promotes the conversion of regulatory T cells from MPE to a Th17-like phenotype by modulating Helios.

Keywords: malignant pleural effusion, lung cancer, IRF4, regulatory $\mathrm{T}$ cells, phenotypic transformation

\section{Introduction}

Malignant pleural effusion (MPE) is a complication of tumors that is most commonly caused by lung cancer. ${ }^{1}$ The immunosuppressive state of the tumor microenvironment represents a challenge to overcoming the current dismal outcome of patients with advanced lung cancer. ${ }^{2-4}$ However, various inhibitory factors derived from immune cells, including tumor-associated macrophages, bone-marrow-derived suppressor cells, and regulatory T cells (Tregs), especially in the intratumoral microenvironment, hinder therapeutic strategies by helping tumor cells to escape immune attack. ${ }^{5,6}$

Studies have found that a variety of $\mathrm{CD}^{+} \mathrm{T}$ cell subsets, are enriched in the MPE of non-small cell lung cancer (NSCLC). ${ }^{4,-10}$ Tregs are a distinct subset of 
$\mathrm{CD}^{+} \mathrm{T}$ cells that function to prevent excessive inflammatory tissue damage and maintain immune tolerance. In addition, Tregs also promote tumor development and progress via both humoral and cellular mechanisms. Tregs facilitate MPE progression in both humans and animal models. ${ }^{4,10,11}$ The alteration of the Treg/Th17 balance in MPE influenced prognosis in patients with lung cancer; ${ }^{12}$ however, the mechanism associated with the immunological abnormalities in the MPE microenvironment remain to be elucidated.

The current findings of Treg cell-based therapy in the context of transplant rejection, autoimmune, and inflammatory diseases, give rise to creative strategies of reducing the adverse reactions of targeted drugs and/or enhancing anti-cancer responses by eliminating or interfering with the functional activities of Tregs. The unique characteristics of Tregs, including phenotypic changes and functional plasticity, without damaging peripheral tolerance, by transforming into effector $\mathrm{T}$ cells to control the function of these inhibitory cells, especially in the intraltumoral tissue, and may provide novel insight and targets for cancer treatment.

There is growing interest in probing into the phenotype, functional stability, or plasticity of Tregs. Recent studies have demonstrated that Foxp $3^{+}$Tregs can be transformed into effector T-like cells (eg, Th1-like or Th17-like Tregs.), which have pro-inflammatory functional characteristics, and are expected to regulate Treg-mediated diseases. ${ }^{13-18}$ Thus, our study focuses on the Treg phenotypes in the MPE and explores the dysfunction of the transcription factor, interferon regulatory factor 4 (IRF4), in affecting changes to the phenotype and suppressive function of Treg cells in the MPE of patients with NSCLC.

\section{Materials and Methods}

\section{Study Subjects}

All study subjects were recruited from the Taizhou People's Hospital from Feb 2018 to Apr 2019, in Taizhou, Jiangsu, China [Table 1]. This study included 30 patients (age range, 43-79 years old) with newly diagnosed MPE from NSCLC, including adenocarcinoma $(\mathrm{n}=$ $25)$ and squamous cell carcinoma $(n=5)$. Another 30 patients with non-malignant pleural effusion including tuberculous pleural effusion $(n=11)$ (age range, 24-78 years old) and parapneumonic effusion $(n=19)$ (age range, 20-78 years old) were also enrolled. Patients with MPE were confirmed by the presence of malignant cells in
Table I Clinical Characteristics of Patients with Pleural Effusion

\begin{tabular}{|l|c|c|}
\hline \multirow{2}{*}{ Variables } & \multicolumn{2}{|c|}{ Number of Patients } \\
\cline { 2 - 3 } & MPE (n=30) & NPE (n=30) \\
\hline Gender & 12 & 15 \\
Male & 18 & 15 \\
\hline Female & & \\
Age, years & 11 & 14 \\
$\geq 60$ & 19 & 16 \\
\hline Pathological type & & \\
Adenocarcinoma & 25 & \\
Squamous cell & 5 & \\
\hline Multiple metastasis & & \\
Yes & 20 & 11 \\
No & 10 & \\
\hline Benign pleural effusion & & \\
Tuberculous & & \\
Pneumonia & & \\
\hline
\end{tabular}

the pleural effusion and/or observed via biopsy histology. In addition, patients with tuberculous fluid were evidenced by Mycobacterium tuberculosis DNA testing, or the effectiveness of diagnostic anti-tuberculosis therapy. Patients were excluded if they underwent any anti-tuberculosis treatment, anticancer therapy, chest trauma, or invasive procedures directed into the pleural cavity.

\section{Sample Processing}

Peripheral venous blood and the pleural fluid were obtained from patients within $24 \mathrm{~h}$ Following admission. At least $100 \mathrm{~mL}$ of pleural fluid was collected from each patient. Peripheral blood mononuclear (PBMC) cells were isolated from the blood samples in NSCLC patients with MPE by density-gradient centrifugation. Pleural effusion mononuclear (PEMC) cells were collected from patients with MPE or NPE using Ficoll-Hypaque gradient (Pharmacia, Uppsala, Sweden). All specimens were processed as previously described. ${ }^{19}$ The harvested PBMCs and PEMCs were washed twice with PBS and counted for subsequent detection.

\section{Flow Cytometry}

All Samples from the resuspended PBMCs or PEMCs were stained with Fc Block $(1 \mu \mathrm{L} / 100 \mathrm{~L})$ (Catalog Number: 554656). The expression of various Treg and Th17 cell markers was measured after immunostaining. 
According to the manufacturer's instructions, CD4-Percpcy $^{\mathrm{TM}} 5.5$ (Catalog Number: 560650) and CD25-BB515 (Catalog Number: 564467) antibodies from BD Biosciences (San Jose, CA, USA) were used for extracellular staining, after which the cells were fixed and permeabilized for intracellular staining with Foxp3-PE (Catalog Number: 320108), Helios-Alexa Fluo 647 (Catalog Number: 563951) and ROR $\gamma t-A l e x a$ Fluor 647 (Catalog Number: 563620) from BD Biosciences (San Jose, CA, USA). Fluorescence activated cell sorting (FACS) cytometer (Becton Dickinson, USA) was used to detect and collect data for analysis by Cell Quest software.

\section{Quantitative Real-Time PCR}

Total RNA from PEMCs was extracted using TRIzol (B511311; Sangon, China) and cDNA was synthesized using a HiScript First Strand cDNA Synthesis Kit (Vazyme, Nanjing, China). RT-PCR was performed using AceQ qPCR SYBR Green Master Mix (Vazyme) on a ABI Prism 7500 PCR System (CA, USA). All primers were purchased from Suchow GENEWIZ Co., Ltd (Suzhou, China), and the reactions were performed in triplicate. The relative level of mRNA was calculated using the $-\Delta \Delta \mathrm{Ct}$ method, where $\Delta \mathrm{Ct}=\mathrm{Ct}$ target gene - $\mathrm{Ct}$ reference). The following primer sequences were used: GAPDH F: 5' GAAGGTCGGAGTCAACGGAT 3', R: 5' CCTGGAAGATGGTGATGGG 3'; IRF4 F: 5' GTGAAA ATGGTTGCCAGGTGA 3', IRF4 R: 5' AGGCTTCGG CAGACCTTATG 3'.

\section{In vitro Treg Induction and Transfection}

$\mathrm{CD} 4^{+} \mathrm{CD} 25^{-} \mathrm{T}$ cells from the PEMCs suspension was purified by magnetic bead sorting according to the manufacturer's protocol. The CD4 T Lym Enrichment IMagDM set (BD, San Jose, CA, USA) was used to isolate $\mathrm{CD}^{+}{ }^{\mathrm{T}}$ cells. Anti-Human CD25 Magnetic Particles-DM (BD, San Jose, CA, USA) was added for negative selection in the magnetic field. The sorted $\mathrm{CD} 4^{+} \mathrm{CD} 25^{-}$ $\mathrm{T}$ cells were cultured after analysis by flow cytometry. These assays were processed as previously described. The sorted cells were cultured in RPMI 1640 media (Life Technologies, Carlsbad, CA, USA) supplemented with $10 \%$ FBS, interleukin-2 (IL-2), TGF- $\beta 1,100 \mathrm{U} / \mathrm{mL}$ penicillin, and $100 \mu \mathrm{g} / \mathrm{mL}$ streptomycin, and stimulated with $1 \mu \mathrm{g} / \mathrm{mL}$ anti-CD3 (OKT3) and $1 \mu \mathrm{g} / \mathrm{mL}$ CD28 (CD28.2) in 48-well plates for 7 days until further assessment by flow cytometry.
The IRF4 and Helios plasmid, as well as the empty plasmid control were synthesized by Sango Biotech. Induced Treg cells (iTregs) were transfected with an IRF4 mimic $(25 \mathrm{nmol} / \mathrm{L})$ or inhibitor $(50 \mathrm{nmol} / \mathrm{L})$, and Helios overexpression plasmid, together with respective negative control using lipofectamine 2000 (Life Technologies). After $48 \mathrm{~h}$, the cells were processed for flow cytometry and qRTPCR analysis. The transfection efficiency was 50\%-60\%.

\section{Ethics Approval}

This study followed the guidelines of the Declaration of Helsinki and was approved by the Ethics Committee of Taizhou People's Hospital (NO.TZ180135). Informed consent was obtained from all subjects included in this study.

\section{Statistical Analysis}

SPSS 17.0 software (IBM Corp., Armonk, NY, USA) was used for statistical analysis. Data are presented as the mean \pm standard deviation. Comparisons between two groups were performed using a Student's $t$-test for normally distributed data. A Mann-Whitney test was used for nonnormally distributed data. The paired Student's $t$ test was used for the paired data comparisons. The possible relationship was analyzed by the spearman rank correlation. Survival rate was assessed by the Kaplan-Meier analysis and compared by the Log rank test. Differences with $P<$ 0.05 were considered statistically significant.

\section{Results}

\section{Tregs and ThI7 Cells are Both Increased in the MPE}

Based on the level of CD4, CD25, Foxp3, Helios, and ROR $\gamma \mathrm{t}$ expression, we performed flow cytometry to visualize Treg and Th17 cell distribution in the MPE. A higher frequency of $\mathrm{CD}^{+} \mathrm{CD} 25^{+} \mathrm{Foxp}^{+} \mathrm{Helios}^{+}$Tregs was observed in the MPE compared to that of the corresponding peripheral blood $(3.08 \% \pm 0.28 \%$ vs $2.18 \% \pm 0.24 \%$, $P<0.01)$ and the NPE $(2.96 \% \pm 0.35 \%$ vs $1.18 \% \pm$ $0.38 \%, P<0.01$ ) (Figures 1 and 2A). Similarly, a significantly increased proportion of $\mathrm{CD}^{+} \mathrm{ROR} \gamma \mathrm{t}^{+}$ Th17 cells was found in the MPE in comparison with that of the corresponding peripheral blood $(2.98 \% \pm$ $0.44 \%$ vs $2.12 \% \pm 0.32 \%, P<0.01)$ and the NPE $(2.94 \% \pm 0.41 \%$ vs $2.37 \% \pm 0.43 \%, P<0.01)$ (Figures 1 and $2 \mathrm{~A})$. 

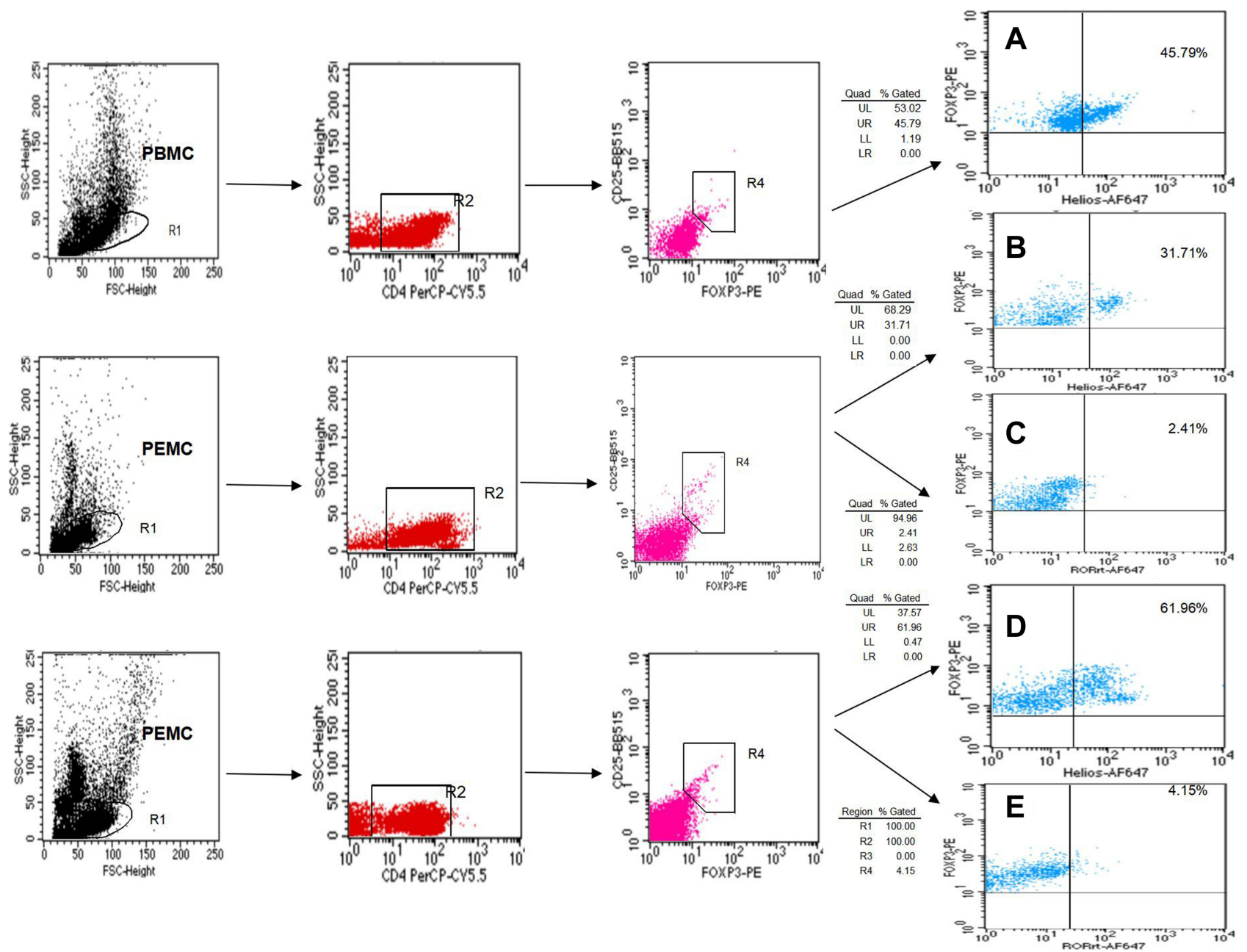

Figure I The percentage of Tregs and Th 17 cells from PBMCs and PEMCs. (A) Dot plots of CD4 $4^{+} \mathrm{CD} 25^{+}$Foxp $3^{+}$Helios ${ }^{+}$Tregs in PBMCs from patients with NSCLC. (B and C) representative dot plots of $\mathrm{CD}^{+} \mathrm{CD} 25^{+} \mathrm{Foxp} 3^{+} \mathrm{Helios}{ }^{+}$Tregs and $\mathrm{CD} 4^{+} \mathrm{CD} 25^{+} \mathrm{Foxp} 3^{+} \mathrm{ROR} \gamma \mathrm{t}^{+}$Tregs in PEMCs from the same patient with NPE, respectively. (D and E) representative dot plots of $\mathrm{CD} 4^{+} \mathrm{CD} 25^{+}$Foxp $3^{+} \mathrm{Helios}^{+}$Tregs and $\mathrm{CD} 4^{+} \mathrm{CD} 25^{+}{ }^{+} \mathrm{Foxp}^{+}{ }^{+} \mathrm{ROR} \gamma \mathrm{t}^{+}$Tregs in the PEMCs from the same patient with NSCLC, respectively.

\section{Th 17/Tregs are Decreased and Associated with Survival Time in Patients with MPE}

The ratio of $\mathrm{CD}^{+}{ }^{+} \mathrm{ROR} \gamma \mathrm{t}^{+}$Th17/CD4 ${ }^{+} \mathrm{CD} 25^{+} \mathrm{Foxp}^{+}$ Tregs in NSCLC patients was lower in the MPE compared to the corresponding PBMCs $(0.62 \% \pm 0.12 \%$ vs $0.51 \% \pm 0.08 \%, P<0.01)$ and the NPE $(0.61 \% \pm$ $0.11 \%$ vs $0.70 \% \pm 0.17 \%, P<0.05$ ) (Figure $2 \mathrm{~A}$ ). We also found that patients with a higher frequency of $\mathrm{CD}^{+} \mathrm{CD} 25^{+} \mathrm{Foxp}^{+}{ }^{+}$Helios ${ }^{+}$Tregs had a shorter survival time in comparison with those with a lower frequency (Figure 2C). Conversely, patients with an elevated ratio of Th17/Tregs had a longer survival time than those with a low ratio (Figure 2D).

\section{CD $4^{+}$CD $25^{+}$Foxp $3^{+}$ROR $\gamma \mathrm{t}^{+} \mathrm{T}$ Cells are Increased in the MPE}

Tregs are a special subgroup of $\mathrm{CD}^{+} \mathrm{T}$ cells with obvious heterogeneity. The transformation of Tregs into effector $\mathrm{T}$ cells and multiple cytokine-producing Teff cell-like Tregs (eg, Th1-like, Th17-like, and Tfh-like) have been observed. However, the specific causes and clinical significance of such transformations remains unclear. We determined the level of $\mathrm{CD} 4^{+} \mathrm{CD} 25^{+} \mathrm{Foxp}^{+}$ Tregs co-expressing ROR $\gamma$ t, which is an important transcription factor for Th17 cells, and identified the presence of $\mathrm{CD}^{+} \mathrm{CD}^{+} 5^{+} \mathrm{Foxp}^{+}{ }^{+} \mathrm{ROR} \gamma \mathrm{t}^{+}$cells $\quad\left(\mathrm{Foxp}^{+}{ }^{+} \mathrm{ROR} \gamma \mathrm{t}^{+}\right.$ Tregs/Th17-like Tregs) in the MPE. The level of ROR $\gamma \mathrm{t}$ 

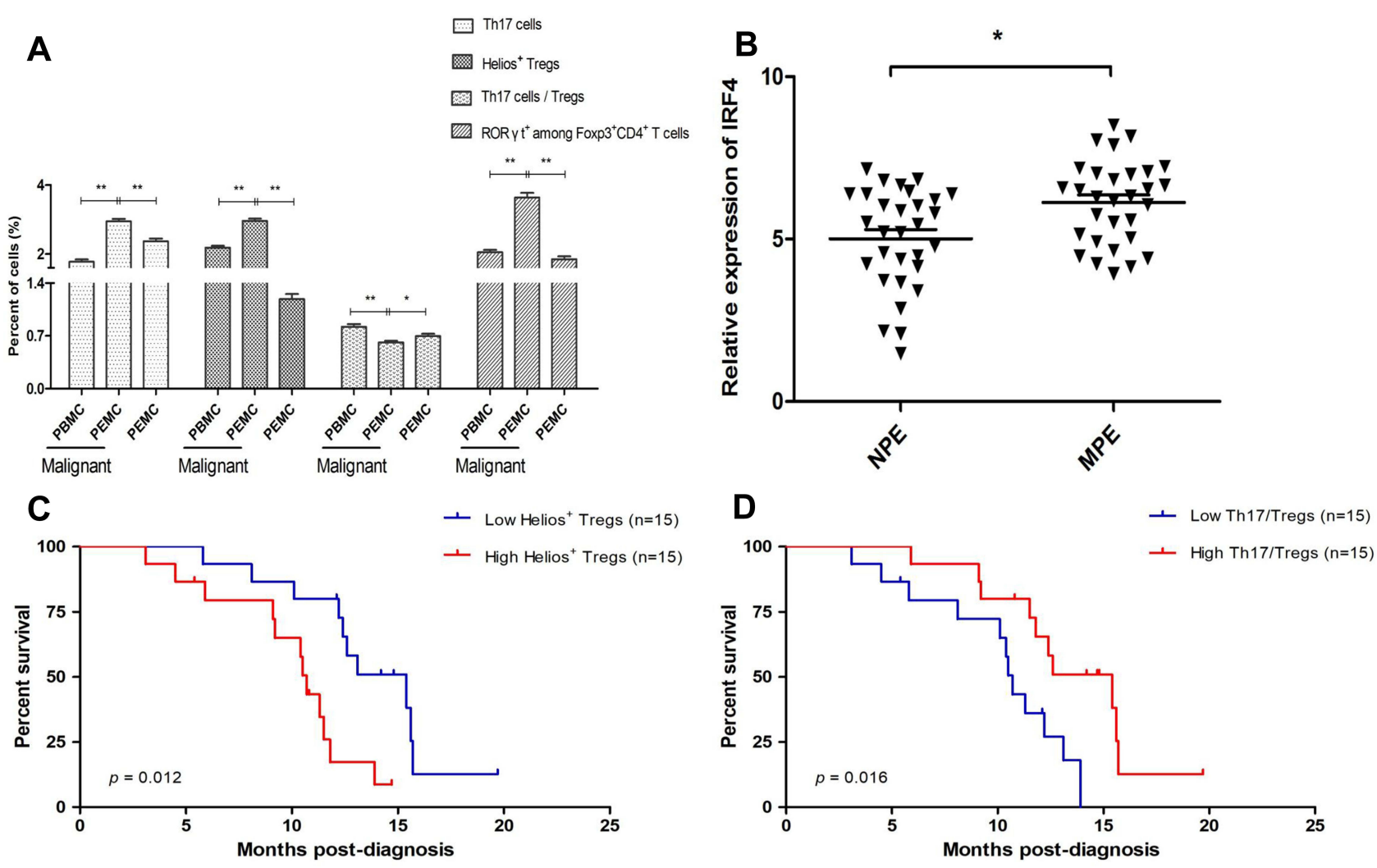

Figure 2 Association between the level of Helios $^{+}$Tregs and the ratio of ThI7/Tregs on patient survival. (A) The proportion of Tregs and ThI7 cells from PBMCs and

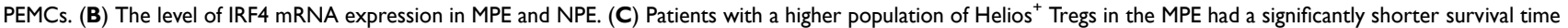
than those with lower population of Helios ${ }^{+}$Tregs $(P=0.012)$. (D) Patients with a high ratio of ThI $7 /$ Tregs in MPE had a longer survival time than those with a low ratio of ThI7/Tregs $(P=0.016)$. $* P<0.05 ; * * P<0.01$.

Abbreviations: PBMCs, peripheral blood mononuclear cells; PEMCs, malignant pleural effusion mononuclear cells; MPE, malignant pleural effusion; NPE, non-malignant pleural effusion; Treg, regulatory T cell.

expression was substantially increased in $\mathrm{CD}^{+} \mathrm{CD} 25^{+} \mathrm{Foxp}^{+}$Tregs from the MPE compared to the levels in the NPE. Notably, a significant increase in $\mathrm{CD} 4{ }^{+} \mathrm{CD} 25^{+} \mathrm{Foxp}^{+}{ }^{+} \mathrm{ROR} \gamma \mathrm{t}^{+}$Tregs was found in the MPE compared with the corresponding PBMCs $(0.18 \% \pm$ $0.04 \%$ vs $0.09 \% \pm 0.01 \%, P<0.01)$ and the NPE $(0.18 \% \pm 0.04 \%$ vs $0.07 \% \pm 0.02 \%, \quad P<0.01)$ (Figures 1, 2A).

\section{IRF4 mRNA Expression and Correlation with CD $4^{+} \mathrm{CD} 25^{+}$Foxp $3^{+} \mathrm{ROR} \gamma \mathrm{t}^{+}$Tregs in the PE}

In light of the critical contribution of IRF4 in the generation and function of Th17 cells, we next investigated the level of IRF4 mRNA expression in the PE. Compared to NPE, the relative level of IRF4 mRNA expression was increased in the MPE $(P<0.05)$ (Figure $2 \mathrm{~B})$. Importantly, the level of IRF4 mRNA expression was positively associated with the percentage of $\mathrm{CD} 4^{+} \mathrm{CD} 25^{+} \mathrm{Foxp}^{+}{ }^{\mathrm{ROR}} \gamma \mathrm{t}^{+}$Tregs in the PE (Figure 3).

\section{IRF4 Affects the Function of iTregs by Regulating Helios Expression and Promoting Phenotypic Changes of iTregs in vitro}

Although the effect of IRF4 on the innate and adaptive immune cells has been investigated, the role of IRF4 in Tregs remains largely unknown. To test whether IRF4 expression regulates the immunosuppressive capacity of Tregs, we evaluated the level of Helios expression, which is related to the phenotypic and functional stability of $\mathrm{CD} 4^{+}$ and $\mathrm{CD}^{+}$Tregs. Based on previous studies, we accessed the level of Helios mRNA and protein expression after induced Tregs were interfered (Figure 4). The level of Helios mRNA was decreased in iTregs following transcription with IRF4 over-expression. Consistent with the level of 


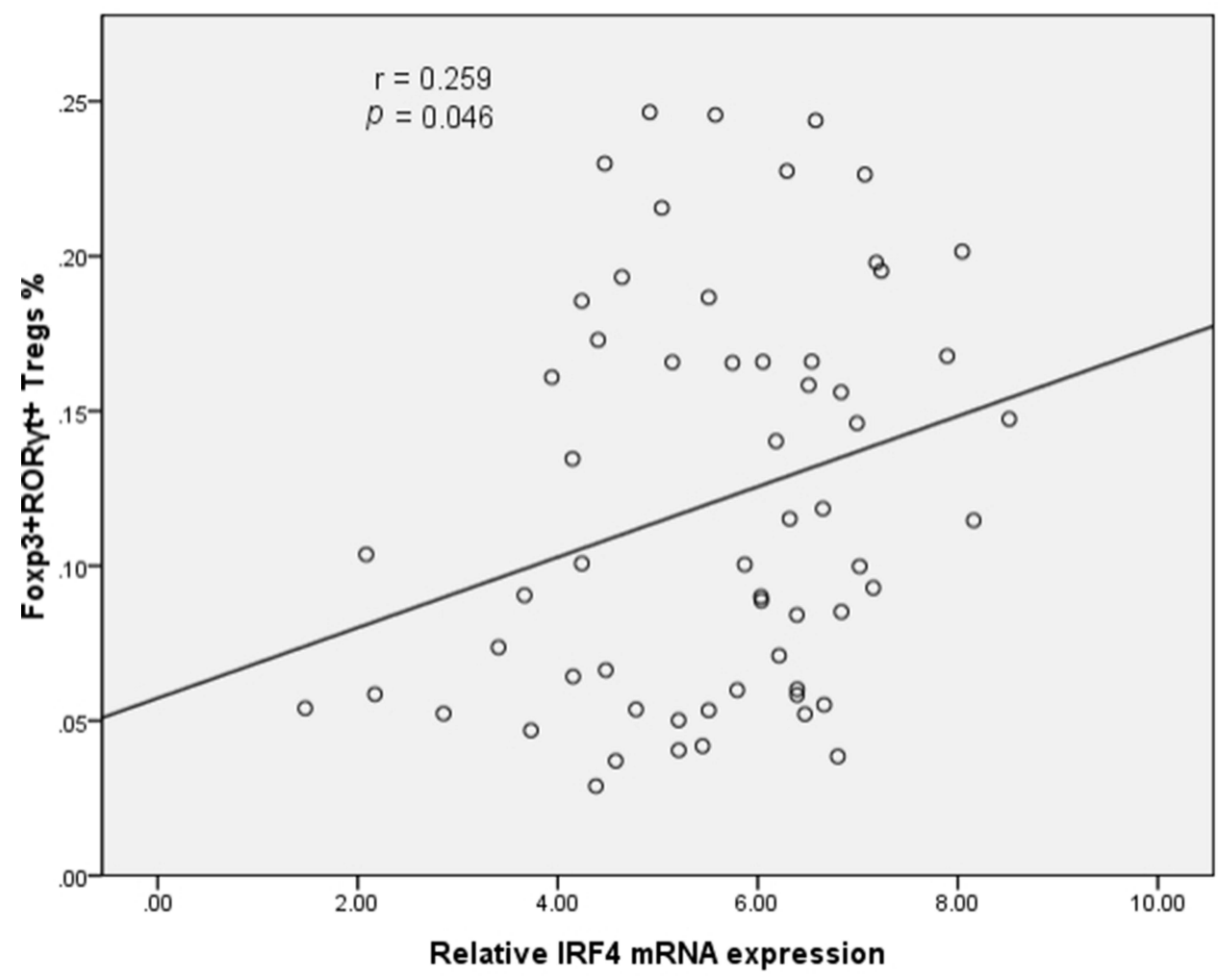

Figure 3 Scatter diagram of the correlation between IRF4 expression and population of Foxp $3^{+}$ROR $\gamma \mathrm{t}^{+}$Tregs. IRF4 expression is positively associated with the frequency of $\mathrm{CD} 4^{+} \mathrm{CD} 25^{+}$Foxp $^{+}{ }^{+} \mathrm{ROR} \gamma \mathrm{t}^{+}$Tregs (60 patients with PE).

mRNA expression, the level of Helios protein expression was also downregulated in the IRF4 over-expressed iTregs $(P<0.001)$ (Figures 5 and 6$)$. In addition, the level of ROR $\gamma \mathrm{t}$ expression, a gene situated downstream of IRF4, was also measured. IRF4 over-expression in iTregs was found to induce a substantial increase in the level of ROR $\gamma \mathrm{t}$ protein expression $(P<0.001)$ (Figure 5).

\section{Discussion}

In this study, we found that both the frequency of $\mathrm{CD}^{+} \mathrm{CD} 25^{+} \mathrm{Foxp}^{+}$Tregs and Helios expression in the MPE of NSCLC patients were significantly higher than that in the peripheral blood and NPE. Previous studies have considered Tregs co-expressing Helios and Foxp3 to be a stronger suppressor subset. ${ }^{20-22}$ Helios ensures the stability of the phenotype and function of CD4 and CD8 Tregs in specific inflammatory environments. ${ }^{20,23}$ Importantly, recent studies have demonstrated that Heliosexpressing Foxp $3^{+}$Tregs are involved in various human disorders, including cancer. $^{24-28}$ For example, Tregs expressing Helios were found to promote the infiltration and metastasis of childhood B-cell precursor acute lymphoblastic leukemia. ${ }^{29}$ In addition, the increased accumulation of the Foxp $3^{+}$Helios ${ }^{+}$Tregs, combined with the expression of a diverse number of suppressive molecules, including PD-1 and CTLA-4, contributed to the establishment of an immune-subversive environment and unfavorable progression in breast cancer and colorectal cancer (CRC). ${ }^{25,30-32}$ These findings provide the possibility for exploring new approaches to the modulation of Treg-mediated immune responses by targeting Helios.

Consistent with the findings of previous studies, ${ }^{8,9,12}$ we also found that while the percentage of Th17 was increased in the MPE, the Th17/Treg ratio was significantly decreased, suggesting that the phenotype of Helios $^{+}$Tregs changed the Th17/Treg balance in the MPE of NSCLC patients. Moreover, patients with a high frequency of $\mathrm{CD}^{+} \mathrm{CD} 25^{+} \mathrm{Foxp}^{+}{ }^{+} \mathrm{Helios}^{+}$Tregs had a shorter survival time than those displaying a low frequency. However, patients with an increased ratio of Th17/ Tregs had a longer survival time compared with that of low patients. A recent clinical study revealed that Tregs expressed ROR $\gamma \mathrm{t}$ and produced IL-17, but exhibited reduced IL-10 production, indicating that there was also a pro-inflammatory subset of Tregs in the peripheral blood of NSCLC patients. ${ }^{33}$ Interestingly, we also detected the 


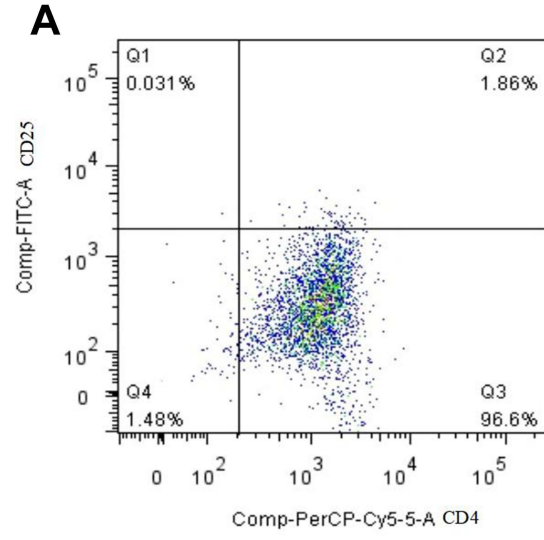

\section{B}

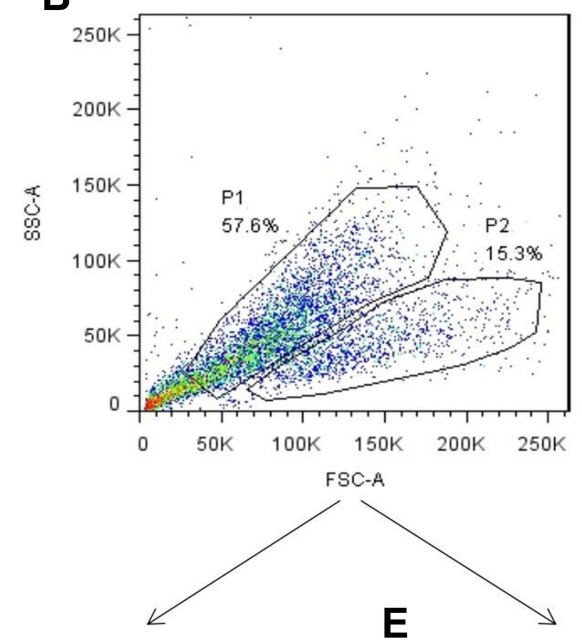

D

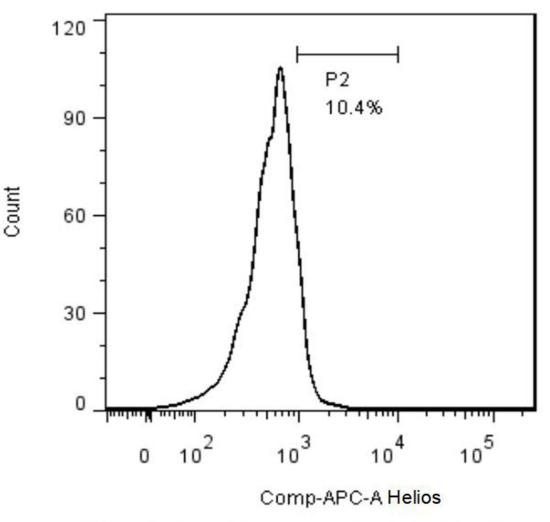

\section{CD4 ${ }^{+}$CD25- $T$ cells}

C

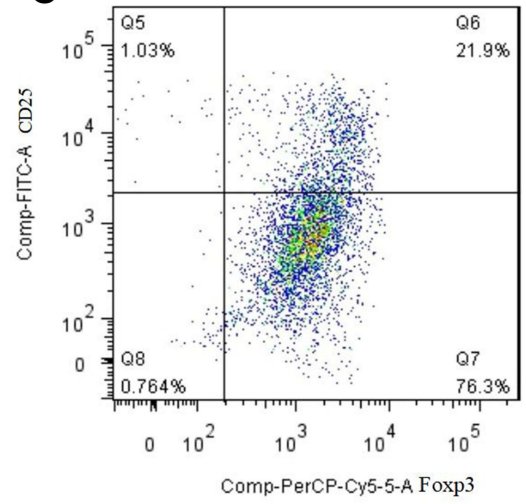

Figure 4 The generation of induced Tregs. (A) Freshly isolated CD4 $4^{+} \mathrm{CD} 25^{-} \mathrm{T}$ cells from PEMCs of an NSCLC patient by magnetic bead sorting. (B and C) CD $4^{+} \mathrm{CD} 25^{+}$Foxp $^{+}$Tregs were produced by cytokine stimulation. (D and E) Helios expression in induced Tregs and non-Tregs, respectively.

presence of ROR $\gamma \mathrm{t}^{+}$Tregs in the MPE, and found that $\mathrm{CD} 4^{+} \mathrm{CD} 25^{+} \mathrm{Foxp}^{+}$Tregs expressed higher levels of ROR $\gamma t$ than that in the NPE. In line with the findings of this previous study, ${ }^{33}$ our results also support the existence of Tregs with phenotypic heterogeneity or functional plasticity in NSCLC patients with MPE. Indeed, another study has suggested that ROR $\gamma t$ and Foxp3 co-expressing Tregs in the peripheral blood of patients with pancreatic cancer exhibited both pro-inflammatory and immunosuppressive features and was involved in disease progression. ${ }^{34}$ In addition, in patients with colon cancer, ROR $\gamma \mathrm{t}^{+} \mathrm{Foxp}^{+}$ cells derived from Foxp3 ${ }^{+}$Tregs have been shown to produce IL-17 and retain inhibitory functions, while also demonstrating an impaired anti-inflammatory response. ${ }^{35}$ In the ascites of patients with ovarian cancer, ${ }^{18}$ a Th17-like Treg subgroup has been identified, and IL- $17 \mathrm{~A}^{+} \mathrm{Foxp} 3^{+}$ $\mathrm{T}$ cells were found to be significantly increased compared with that in the peripheral blood. Moreover, in tumor- bearing mouse models, Th17-to-Treg cell switching is also a source of tumor-associated Tregs. ${ }^{18}$ Therefore, we speculate that Tregs expressing ROR $\gamma t$ may be associated with phenotypic and/or functional adaptability changes in the MPE inflammatory environment; however, the underlying mechanism and precise role require further study.

IRF4 is a member of the IRF family (IRF1-10) that serves as an essential transcriptional modulator that can orchestrate the actions of various immune cells, including macrophages, dendritic cells, and both $\mathrm{B}$ and T lymphocytes. ${ }^{36-40}$ Notably, IRF4 is also a functional determinant of Tregs. ${ }^{41,42}$ In this study, our findings support the abnormal expression of IRF4 in the MPE. Importantly, IRF4 not only decreased the level of Helios mRNA and protein expression, but also promoted ROR $\gamma \mathrm{t}$ expression, which induced a remarkable phenotypic change in induced Tregs. In addition, increased ROR $\gamma \mathrm{t}^{+} \mathrm{Foxp}^{+}$Tregs were associated with IRF4 over- 

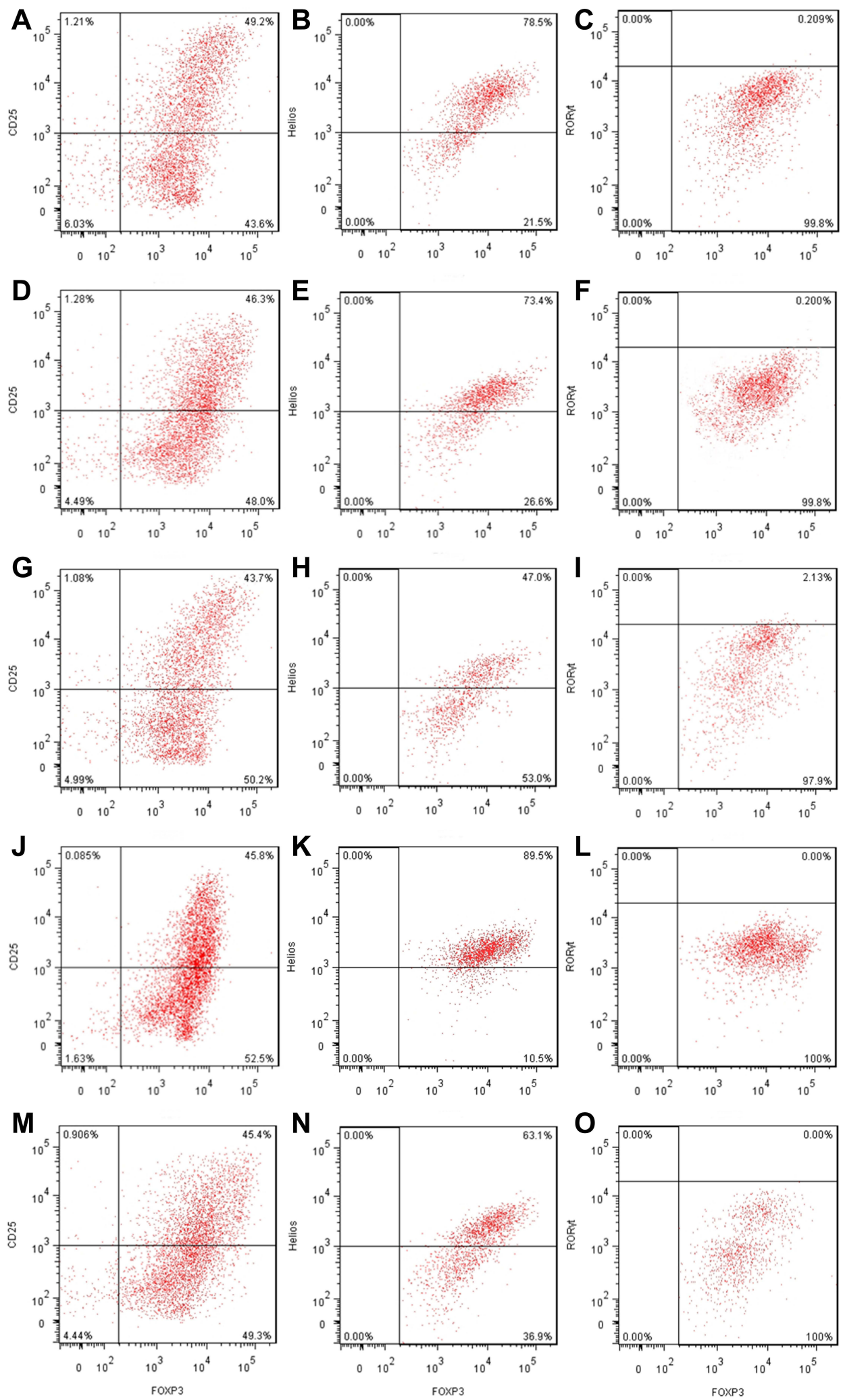

Figure 5 The effects of IRF4 on the function of induced Tregs. (A-C) The level of Helios and ROR $\gamma \mathrm{t}$ protein expression in induced CD4 ${ }^{+} \mathrm{CD} 25^{+}$Foxp $3^{+}$Tregs transfected with negative controls (Helios: $78.5 \%$, ROR $\gamma$ t: $0.209 \%$ ). (D-F) The level of Helios and ROR $\gamma \mathrm{t}$ protein expression in induced CD4 ${ }^{+} \mathrm{CD} 25^{+}$Foxp $3^{+}$Tregs transfected with IRF4 control (Helios: $73.4 \%$, ROR $\gamma$ t: $0.200 \%$ ). (G-I) The level of Helios and ROR $\gamma$ t protein expression in induced CD4 ${ }^{+}$CD2 $5^{+}$Foxp $3^{+}$Tregs transfected with enhanced IRF4 (Helios: 47.0\%, ROR $\gamma$ t: 2.13\%). (J-L) The level of Helios and ROR $\gamma$ t protein expression in induced CD $4^{+} \mathrm{CD} 25^{+}$Foxp $3^{+}$Tregs transfected with an IRF4 inhibitor (Helios: 89.5\%, ROR $\gamma$ t: $0.00 \%$ ). (M-O) The level of Helios and ROR $\gamma$ t protein expression in induced CD $4^{+} \mathrm{CD} 25^{+}$Foxp $3^{+}$Tregs transfected with enhanced IRF4 and Helios overexpression (Helios: $63.1 \%$, ROR $\gamma$ t: $0.00 \%$ ). 


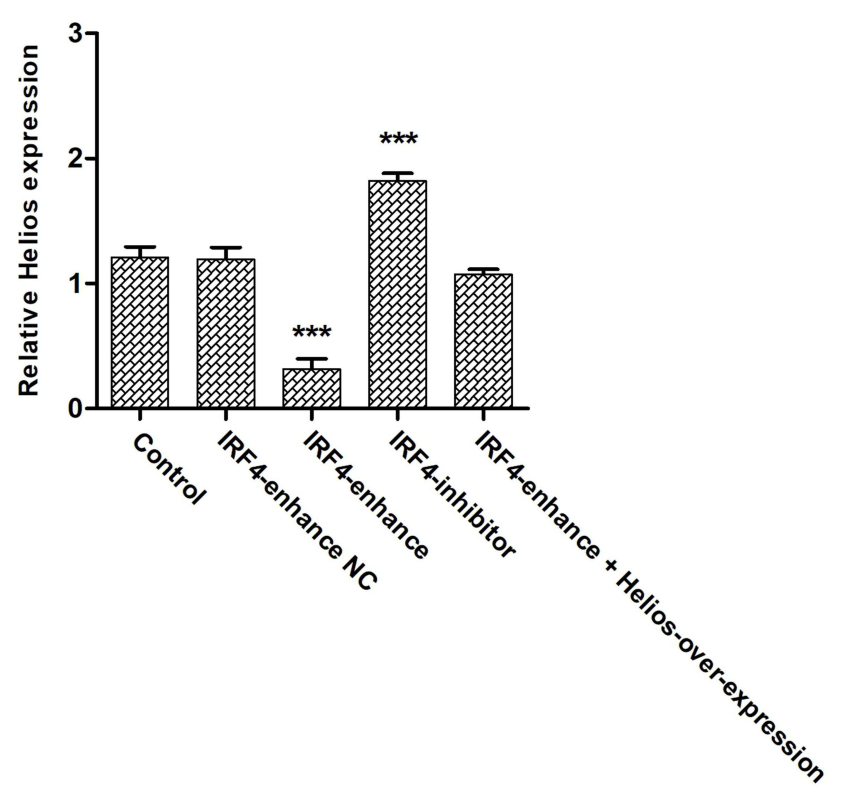

Figure 6 The level Helios expression in induced Tregs after IRF4 interference. The cumulative data showing the relative level of Helios mRNA expression in induced Tregs treated with enhanced IRF4, an IRF4 inhibitor, and respective negative controls. $* * * P<0.001$.

expression in the PE. A recent study showed that IRF4 dysfunction impaired the immunosuppressive function of Tregs by affecting the metabolism and secretion of IL-10 in newly diagnosed primary immune thrombocytopenia (ITP) patients. ${ }^{43}$ However, a Treg-specific deletion of IRF4 leads to a selective dysregulation of the Th2 response, IL-4-dependent immunoglobulin isotype production, and obvious tissue damage by plasma cell infiltration, indicating a functional requirement for IRF4 in suppressing the Th12 response. ${ }^{44}$ Additionally, the interaction between IRF4 and basic leucine zipper transcription factor ATF-like cooperatively supported the differentiation and maintenance of specialized Tregs in visceral adipose tissue through inducing the expression of ST2 and PPAR- $\gamma^{45}$ This indicates that IRF4 and additional molecules associated with Treg transcription mechanisms either cooperatively or competitively affect Treg phenotypic plasticity or functional stability, as well as the corresponding immune response. ${ }^{44}$

\section{Conclusion}

In conclusion, the presence of $\mathrm{CD} 4^{+} \mathrm{CD} 25^{+} \mathrm{Foxp} 3^{+} \mathrm{ROR} \gamma \mathrm{t}^{+}$ cells (Foxp ${ }^{+}{ }^{\text {ROR }} \gamma \mathrm{t}^{+}$Tregs/ Th17-like Tregs) as a subset of Tregs was identified in the PE. In the MPE of NSCLC patients, increased ROR $\gamma \mathrm{t}^{+}$Foxp $3^{+}$Tregs also suggested a phenotypic transition of conventional Tregs. Additionally, the level of ROR $\gamma \mathrm{t}$ expression in
$\mathrm{CD} 4^{+} \mathrm{CD} 25^{+} \mathrm{Foxp}^{+}$Tregs was positively associated with IRF4 expression in the PE. Mechanically, the transcription factor, IRF4, can affect the phenotype and suppressive function of Treg cells in MPE of patients with NSCLC by downregulating Helios. The results of the present study indicate that IRF4 might represent a potential molecule that can promote the conversion of a Th17-like phenotype in Tregs derived from MPE.

\section{Acknowlegements}

This research was supported by grants from the Precision Medicine Research of The National Key Research and Development Plan of China (No.2016YFC0905800), the National Natural Science Foundation of China (No.81970031, 81770031, 81700028, 81800090), National Science Foundation of Jiangsu Province (No. BK20171501, BK20171080, BK20181497), and Scientific research funding of Taizhou people's Hospital (ZL202014 and ZL202026).

\section{Author Contributions}

All authors contributed to data analysis, drafting or revising the article, gave final approval of the version to be published, agreed to the submitted journal, and agree to be accountable for all aspects of the work.

\section{Disclosure}

The authors report no conflicts of interest in this work.

\section{References}

1. Koegelenberg C, Shaw JA, Irusen EM, Lee Y. Contemporary best practice in the management of malignant pleural effusion. Ther $A d v$ Respir Dis. 2018;12:1024447158. doi:10.1177/1753466618785098

2. Egen JG, Ouyang W, Wu LC. Human anti-tumor immunity: insights from immunotherapy clinical trials. Immunity. 2020;52:36-54. doi:10.1016/j.immuni.

3. Binnewies M, Roberts EW, Kersten K, et al. Understanding the tumor immune microenvironment (TIME) for effective therapy. Nat Med. 2018;24:541-550. doi:10.1038/s41591-018-0014-x

4. Budna J, Kaczmarek M, Kolecka-Bednarczyk A, et al. Enhanced suppressive activity of regulatory $\mathrm{T}$ cells in the microenvironment of malignant pleural effusions. J Immunol Res. 2018;2018:9876014. doi:10.1155/2018/9876014

5. Oliver AJ, Lau P, Unsworth AS, et al. Tissue-dependent tumor microenvironments and their impact on immunotherapy responses. Front Immunol. 2018;9:70. doi:10.3389/fimmu.2018.00070.

6. Sarode P, Schaefer MB, Grimminger F, Seeger W, Savai R. Macrophage and tumor cell cross-talk is fundamental for lung tumor progression: we need to talk. Front Oncol. 2020;10:324. doi:10.3389/ fonc. 2020.00324

7. Chen YQ, Shi HZ, Qin XJ, et al. $\mathrm{CD}^{+} \mathrm{CD} 25^{+}$regulatory $\mathrm{T}$ lymphocytes in malignant pleural effusion. Am J Respir Crit Care Med. 2005;172:1434-1439. doi:10.1164/rccm.200504-588OC 
8. Ye ZJ, Zhou Q, Zhang JC, et al. CD39 ${ }^{+}$regulatory T cells suppress generation and differentiation of Th17 cells in human malignant pleural effusion via a LAP-dependent mechanism. Respir Res. 2011;12:77. doi:10.1186/1465-9921-12-77.

9. Ye ZJ, Zhou Q, Gu YY, et al. Generation and differentiation of IL-17producing $\mathrm{CD}^{+} \mathrm{T}$ cells in malignant pleural effusion. J Immunol. 2010;185:6348-6354. doi:10.4049/jimmunol.1001728

10. Wu XZ, Zhai K, Yi FS, et al. IL-10 promotes malignant pleural effusion in mice by regulating TH1- and TH17-cell differentiation and migration. Eur J Immunol. 2019;49:653-665. doi:10.1002/ eji.201847685

11. Budna J, Spychalski L, Kaczmarek M, et al. Regulatory T cells in malignant pleural effusions subsequent to lung carcinoma and their impact on the course of the disease. Immunobiology. 2017;222:499-505. doi:10.1016/j.imbio.2016.10.017

12. Yang G, Li H, Yao Y, Xu F, Bao Z, Zhou J. Th17 imbalance in malignant pleural effusion partially predicts poor prognosis. Oncol Rep. 2015;33:478-484. doi:10.3892/or.2014.3576.

13. Rocamora-Reverte L, Tuzlak S, von Raffay L, et al. Glucocorticoid Receptor-Deficient Foxp3(+) Regulatory T Cells Fail to Control Experimental Inflammatory Bowel Disease. Front Immunol. 2019;10:472. doi:10.3389/fimmu.2019.00472.

14. Kluger MA, Nosko A, Ramcke T, et al. RORgammat expression in Tregs promotes systemic lupus erythematosus via IL-17 secretion, alteration of Treg phenotype and suppression of Th2 responses. Clin Exp Immunol. 2017;188:63-78. doi:10.1111/cei.1290

15. Ren J, Li B. The Functional Stability of FOXP3 and RORgammat in Treg and Th17 and Their Therapeutic Applications. Adv Protein Chem Struct Biol. 2017;107:155-189. doi:10.1016/bs. apcsb.2016.10.002

16. Nakagawa H, Sido JM, Reyes EE, Kiers V, Cantor H, Kim HJ. Instability of Helios-deficient Tregs is associated with conversion to a T-effector phenotype and enhanced antitumor immunity. Proc Natl Acad Sci U S A. 2016;113:6248-6253. doi:10.1073/pnas.1604765113

17. Dominguez-Villar M, Hafler DA. Regulatory T cells in autoimmune disease. Nat Immunol. 2018;19:665-673. doi:10.1038/s41590-0180120-4

18. Downs-Canner S, Berkey S, Delgoffe GM, et al. Suppressive IL-17A $(+)$ Foxp3(+) and ex-Th17 IL-17A(neg)Foxp3(+) Treg cells are a source of tumour-associated Treg cells. Nat Commun. 2017;8:14649. doi:10.1038/ncomms 14649 .

19. Yu WQ, Ji NF, Gu CJ, et al. Downregulation of miR-4772-3p promotes enhanced regulatory $\mathrm{T}$ cell capacity in malignant pleural effusion by elevating Helios levels. Chin Med J. 2019;132:2705-2715. doi:10.1097/CM9.0000000000000517.

20. Thornton AM, Lu J, Korty PE, et al. Helios(+) and Helios(-) Treg subpopulations are phenotypically and functionally distinct and express dissimilar TCR repertoires. Eur $J$ Immunol. 2019;49:398-412. doi:10.1002/eji.201847935

21. Sugita K, Hanakawa S, Honda T, et al. Generation of Helios reporter mice and an evaluation of the suppressive capacity of Helios $(+)$ regulatory $\mathrm{T}$ cells in vitro. Exp Dermatol. 2015;24:554-556. doi:10.1111/exd.12711

22. Seng A, Krausz KL, Pei D, et al. Coexpression of FOXP3 and a Helios isoform enhances the effectiveness of human engineered regulatory T cells. Blood Adv. 2020;4:1325-1339. doi:10.1182/ bloodadvances

23. Kim HJ, Barnitz RA, Kreslavsky T, et al. Stable inhibitory activity of regulatory $\mathrm{T}$ cells requires the transcription factor Helios. Science. 2015;350:334-339. doi:10.1126/science.aad0616

24. Khaitan A, Kravietz A, Mwamzuka M, et al. FOXP ${ }^{+}$Helios $^{+}$ Regulatory T Cells, Immune Activation, and Advancing Disease in HIV-Infected Children. $J$ Acquir Immune Defic Syndr. 2016;72:474-484. doi:10.1097/QAI.0000000000001000
25. Syed KA, Toor SM, El SH, Ali BR, Elkord E. Intratumoral FoxP3(+) Helios(+) Regulatory $\mathrm{T}$ Cells Upregulating Immunosuppressive Molecules Are Expanded in Human Colorectal Cancer. Front Immunol. 2017;8:619. doi:10.3389/fimmu.2017.00619

26. Toor SM, Murshed K, Al-Dhaheri M, Khawar M, Abu NM, Elkord E. Immune Checkpoints in Circulating and Tumor-Infiltrating CD4(+) T Cell Subsets in Colorectal Cancer Patients. Front Immunol. 2019;10:2936. doi:10.3389/ fimmu.2019.02936

27. Long Y, Zhao X, Xia C, Liu X, Fan C, Liu C. Infection of Epstein-Barr Virus is Associated with the Decrease of Helios(+) FoxP3(+)Regulatory T Cells in Active Ulcerative Colitis Patients. Immunol Invest. 2021;50(1):23-36. doi:10.1080/08820139.20 20.1723021

28. Trojan K, Zhu L, Aly M, et al. Association of peripheral NK cell counts with Helios(+) IFN-gamma(-) Tregs in patients with good long-term renal allograft function. Clin Exp Immunol. 2017;188:467-479. doi:10.1111/cei.12945

29. Li X, Li D, Huang X, et al. Helios expression in regulatory T cells promotes immunosuppression, angiogenesis and the growth of leukemia cells in pediatric acute lymphoblastic leukemia. Leuk Res. 2018;67:60-66. doi:10.1016/j.leukres.2018.02.007.

30. Syed KA, Toor SM, El SH, et al. Preferential accumulation of regulatory $\mathrm{T}$ cells with highly immunosuppressive characteristics in breast tumor microenvironment. Oncotarget. 2017;8:33159-33171. doi:10.18632/oncotarget. 16565

31. Timperi E, Pacella I, Schinzari V, et al. Regulatory $\mathrm{T}$ cells with multiple suppressive and potentially pro-tumor activities accumulate in human colorectal cancer. Oncoimmunology. 2016;5:e1175800. doi:10.1080/2162402X.2016.1175800.

32. Kovacsovics-Bankowski M, Chisholm L, Vercellini J, et al. Detailed characterization of tumor infiltrating lymphocytes in two distinct human solid malignancies show phenotypic similarities. J Immunother Cancer. 2014;2:38. doi:10.1186/s40425-014-0038-9.

33. Phillips JD, Knab LM, Blatner NR, et al. Preferential expansion of pro-inflammatory Tregs in human non-small cell lung cancer. Cancer Immunol Immunother. 2015;64:1185-1191. doi:10.1007/s00262-0151725-1.

34. Chellappa S, Hugenschmidt H, Hagness M, et al. Regulatory T cells that co-express RORgammat and FOXP3 are pro-inflammatory and immunosuppressive and expand in human pancreatic cancer. Oncoimmunology. 2016;5:e1102828. doi:10.1080/2162402X.20 15.1102828 .

35. Blatner NR, Mulcahy MF, Dennis KL, et al. Expression of RORgammat marks a pathogenic regulatory $\mathrm{T}$ cell subset in human colon cancer. Sci Transl Med. 2012;4:159r-164r. doi:10.1126/ scitranslmed.3004566.

36. Wu J, Zhang H, Shi X, et al. Ablation of Transcription Factor IRF4 Promotes Transplant Acceptance by Driving Allogenic CD4(+) T Cell Dysfunction. Immunity. 2017;47:1114-1128. doi:10.1016/j. immuni.2017.11.003.

37. Biswas PS, Bhagat G, Pernis AB. IRF4 and its regulators: evolving insights into the pathogenesis of inflammatory arthritis? Immunol Rev. 2010;233:79-96.

38. Man K, Gabriel SS, Liao Y, et al. Transcription Factor IRF4 Promotes CD8(+) T Cell Exhaustion and Limits the Development of Memory-like $\mathrm{T}$ Cells during Chronic Infection. Immunity. 2017;47:1129-1141. doi:10.1016/j.immuni.2017.11.02.

39. Nam S, Lim JS. Essential role of interferon regulatory factor 4 (IRF4) in immune cell development. Arch Pharm Res. 2016;39:1548-1555. doi:10.1007/s12272-016-0854-1

40. Shaffer AL, Emre NC, Lamy L, et al. IRF4 addiction in multiple myeloma. Nature. 2008;454:226-231. doi:10.1038/nature07064. 
41. Koizumi SI, Sasaki D, Hsieh TH, et al. JunB regulates homeostasis and suppressive functions of effector regulatory $\mathrm{T}$ cells. Nat Commun. 2018;9:5344. doi:10.1038/s41467-018-07735-4

42. Alvisi G, Brummelman J, Puccio S, et al. IRF4 instructs effector Treg differentiation and immune suppression in human cancer. $J$ Clin Invest. 2020;130:3137-3150. doi:10.1172/JCI130426

43. Tang M, Cheng L, Li F, et al. Transcription Factor IRF4 Dysfunction Affects the Immunosuppressive Function of Treg Cells in Patients with Primary Immune Thrombocytopenia. Biomed Res Int. 2019;2019:1050285. doi:10.1155/2019/105028
44. Zheng Y, Chaudhry A, Kas A, et al. Regulatory T-cell suppressor program co-opts transcription factor IRF4 to control $\mathrm{T}(\mathrm{H}) 2$ responses. Nature. 2009;458:351-356. doi:10.1038/nature07674.

45. Vasanthakumar A, Moro K, Xin A, et al. The transcriptional regulators IRF4, BATF and IL-33 orchestrate development and maintenance of adipose tissue-resident regulatory T cells. Nat Immunol. 2015;16:276-285. doi:10.1038/ni.3085

\section{Publish your work in this journal}

The International Journal of General Medicine is an international, peer-reviewed open-access journal that focuses on general and internal medicine, pathogenesis, epidemiology, diagnosis, monitoring and treatment protocols. The journal is characterized by the rapid reporting of reviews, original research and clinical studies across all disease areas. The manuscript management system is completely online and includes a very quick and fair peer-review system, which is all easy to use. Visit http://www.dovepress.com/ testimonials.php to read real quotes from published authors.

Submit your manuscript here: https://www.dovepress.com/international-journal-of-general-medicine-journal 